\title{
Effect of Clinical and Attitudinal Characteristics on Obtaining Comprehensive Medication Reviews
}

\author{
Karen B. Farris, PhD; Teresa M. Salgado, PhD; Nadia Aneese, PharmD; \\ Vincent D. Marshall, MS; Jane F. Pendergast, PhD; Jessica Frank, PharmD; \\ Elizabeth A. Chrischilles, PhD; and William R. Doucette, PhD
}

\begin{abstract}
BACKGROUND: Comprehensive medication reviews (CMRs) consist of indepth reviews of patients' medications to identify effectiveness or safety problems and often generate cost savings for individuals. Despite their advantages, CMRs are not widely obtained. Previous studies found that older age, female sex, and experience of side effects were associated with obtaining a medication review.
\end{abstract}

OBJECTIVE: To quantify the association between attitudinal and clinical factors with intention and predict future behavior to obtain a CMR among Medicare Part $D$ beneficiaries.

METHODS: A sample of Medicare Part $D$ beneficiaries from 1 health care plan $(n=660)$ completed a 14-item survey over the telephone assessing factors that were hypothesized to affect their intention and behavior to obtain a CMR. The survey collected medication use history and health care information with the medication user self-evaluation tool, health status, adherence, intention to obtain a CMR, and demographic characteristics. Subjects subsequently were informed that they could obtain a CMR from their pharmacies. Claims data were obtained that indicated which subjects received a CMR. Two dependent variables were predicted: intention to schedule a CMR using a multivariate linear regression model and receipt of a CMR using a logistic regression and including intention as a predictor variable.

RESULTS: The mean age of participants was $76.6(\mathrm{SD}=7.61)$ years; $71 \%$ were female; and participants took an average of $5.2(S D=3.18)$ medications. The intention to have a CMR was $2.85(S D=1.41)$ on a 5 -point scale, and $5.6 \%$ of the participants actually had a CMR. Worrying about medications doing more harm than good, number of pharmacies where participants obtained their medications from, number of medications, and number of medical conditions predicted intention to obtain a CMR. Patients who perceived their health status to be poorer compared with others their age were more likely to have a CMR. Intention to obtain a CMR was not associated with receipt of a CMR.

CONCLUSIONS: Stakeholders should target patients who perceive their health to be poor for a CMR, hence expanding the scope of CMRs and increasing the number of older adults benefiting from this service.

J Manag Care Spec Pharm. 2016;22(4):388-95

Copyright $\odot 2016$, Academy of Managed Care Pharmacy. All rights reserved.

\section{What is already known about this subject}

Comprehensive medication reviews (CMRs) are 1 of the core elements for medication therapy management (MTM) services and present several advantages to patients and the health care system. However, patient participation in CMRs is low.
The identification of target beneficiaries for MTM services is currently done using prescription claims databases that do not contain specific clinical data or medication-taking behaviors obtained by patient report.

The medication user self-evaluation (MUSE) tool was developed to collect patient-reported information to stimulate CMRs among Medicare Part D beneficiaries.

\section{What this study adds}

This study assessed the influence of other variables beyond the ones tested with the MUSE tool in the behavior of patients obtaining a CMR.

A positive relationship was identified between patients who reported poorer health status and having a CMR.

Patient self-report information can be used by health plans and other stakeholders to target Medicare Part D beneficiaries for CMRs.

$\mathrm{M}$ edicare Part D is the federal program initiated in 2006 that subsidizes the costs of prescription drug coverage to Medicare enrollees via contracts with insurance companies (Part D sponsors), and it was enacted via the Medicare Prescription Drug, Improvement, and Modernization Act in 2003. ${ }^{1}$ Medication therapy management (MTM) services are part of the Medicare Part D program, and the MTM service model includes 5 core elements: (1) a comprehensive medication review (CMR); (2) the provision of a personal medication record; (3) the construction of a medication-related action plan consisting of a list of actions for patients to track progress for self-management; (4) an intervention to address medicationrelated problems or referral to a physician or other health care professional; and (5) documentation of MTM services and follow-up visit. ${ }^{2,3}$ The 2015 Medicare contract for MTM services defined the following specific criteria for MTM program eligibility: having at least 3 chronic diseases (e.g., hypertension, diabetes, dyslipidemia, end-stage renal disease, chronic heart failure, respiratory disease, bone disease-arthritis, Alzheimer's disease, or mental health disorders), taking multiple Part D drugs, and being likely to incur greater than or equal to $\$ 3,138$ in medication expenses in 2015. ${ }^{4}$ Once beneficiaries fulfill these criteria, they are automatically enrolled in MTM. These restrictive criteria, however, have been recently questioned. ${ }^{5}$ 
The core element for MTM services is the CMR, and Part D sponsors are required to offer a CMR at least annually, or quarterly targeted medication reviews, to beneficiaries as part of their contracts with Medicare. ${ }^{2}$ CMRs consist of an interactive, person-to-person or telehealth medication review of the beneficiary's profile including prescription medications, over-the-counter medications, natural therapies, or supplements. Overall, the ultimate goal of a CMR is to assess medication therapy and optimize patient outcomes. Previous research has demonstrated economic advantages from offering medication reviews to patients including a mean cost saving of $\$ 60$ per patient per year ${ }^{6}$ or $£ 307$ per patient during a 6 -month period. ${ }^{7}$ Recent studies demonstrated that MTM interventions were associated with a decrease in MTM members' overall employer-paid and plan-paid health care costs. ${ }^{8,9}$ In addition, a 10-year analysis of the impact of MTM services delivery showed improved clinical outcomes in addition to the cost savings. ${ }^{10}$ Specific benefits for the patient obtaining a CMR include the identification of safety issues (e.g., drug interactions, duplications, adverse drug reactions, unnecessary drugs, or excessive dose or duration of therapy) and effectiveness issues (e.g., suboptimal drug selection, insufficient dose or duration of therapy), as well as less expensive alternative medicines. ${ }^{11}$ From a health care system perspective, medication reviews have reduced emergency hospital admissions, ${ }^{7}$ increased medication adherence, ${ }^{7,12}$ and helped guide more interactive discussions between physicians and patients. ${ }^{11}$

Despite the benefits of CMRs, the number of patients who actually have a CMR performed is low, ${ }^{6,11,13}$ either because it is perceived as unnecessary or because patients are unaware of it. ${ }^{11}$ Research on attitudes for obtaining a CMR showed that participants were willing to have a CMR conducted if they were concerned about their health, ${ }^{6}$ felt their medication burden was high, ${ }^{6}$ experienced side effects, ${ }^{6}$ had a desire for more medication education regarding the safety and efficacy of their treatments, ${ }^{6,11}$ or wanted to save money on their prescription medicines. ${ }^{11}$ In addition, patients acknowledged the benefit of receiving a medication list and having pharmacists and physicians discussing changes to their medications as a consequence of having a CMR. ${ }^{6}$ Potential out-of-pocket cost for a CMR was an important consideration for beneficiaries of Medicare Part D to decide to receive a CMR. ${ }^{14}$ However, considering that this service is currently free for Medicare beneficiaries, out-of-pocket costs should not be an issue.

Gaining insight into factors influencing a patient's intention to obtain a CMR and the actual behavior of receiving one can help payers target these individuals, allowing for proper resource allocation and expansion of CMR services. The identification of target beneficiaries for MTM services is presently done using prescription claims databases, but these databases may not contain specific clinical data or medicationtaking behaviors that can only be obtained by patient report. In
Part D prescription drug plans, for example, prescription claims data allow the determination of the number of medications, costs of medications, number of physicians following the patient, number of pharmacies where patients obtained their medications, and medication possession of each medication to target beneficiaries for CMR. In Medicare Advantage prescription drug plans, additional variables such as number of hospitalizations in the past 6 months and uncontrolled disease (if clinical data are accessed) may be used. What is missing from these data are measures reported by patients such as patients forgetting to take their medications and patients not filling prescriptions due to cost. The purpose of this study was to quantify the association between patient attitudinal and clinical factors with intention to obtain and the actual behavior of obtaining a CMR among eligible patients with Medicare Part D. This study hypothesizes that patient-related factors other than data available from claims databases will predict patients' intention and behavior to obtain a CMR.

\section{Methods}

\section{Study Design and Subjects}

The data used for this analysis were collected as part of a larger study that aimed to improve the targeting of Medicare Part D beneficiaries for MTM services, to enhance MTM service delivery by pharmacists, and to engage Medicare Part D beneficiaries in the medication management process. ${ }^{15,16}$ The larger study was a prospective trial conducted in 2010 and 2011 consisting of a survey, the medication user self-evaluation (MUSE) tool, ${ }^{15}$ administered over the telephone to a sample of 1,015 patients from an original pool of 6,090 individuals (acceptance rate, $16.7 \%) .{ }^{16}$ The individuals were Medicare Part D beneficiaries in 2 health plans with MTM services provided by Outcomes MTM. The initial pool of participants was selected on the basis of the following 3 criteria: being at least 65 years old, having received at least 12 prescription fills of any medication during a 6-month preintervention period (April 1 to September 30 in 2010 and 2011), and having evidence of continuous enrollment over the time frame of interest (2 prescription fills at least 150 days apart). The MUSE survey collected data that were hypothesized to affect the likelihood of participants to obtain a CMR. At the end of the call, CMRs were explained to participants, who were then told whether they had a high, moderate, or low likelihood to benefit from receiving a CMR based on a validated prediction equation that was previously developed. ${ }^{15}$ CMR appointments were not made during the telephone call; rather, it was left to the participants' discretion to schedule a CMR with their pharmacists after the call. After the questionnaire administration via the telephone, Outcomes MTM provided claims to the research team for a period of 6 months following survey completion to determine which individuals obtained a CMR. The 6-month period was judged to allow sufficient time for potential beneficiaries to complete a CMR if 
they wished to do so, but not so long as to be unrelated to the MUSE intervention. CMRs performed outside this observation window were not counted. The results from this trial, which determined the impact of the call/risk score intervention versus no intervention, have been reported elsewhere. ${ }^{16}$

In the present analysis, the same methodology was used, but other factors hypothesized to affect the likelihood of participants to obtain a CMR were tested in addition to those in the MUSE tool. One such important factor was the participant's intention to schedule a CMR. Data about pharmacies and beneficiaries were obtained for one of the health plans in the larger study, providing complete data for 662 participants. Ethics approval for the study was obtained from the institutional review boards of the authors' affiliating institutions.

\section{Data Collection}

During the telephone contact, a 14-item survey was administered to collect medication use history and other health care information. Medication use history and health care information were obtained by administering the 7-item MUSE tool, ${ }^{15}$ which consists of the following questions:

- "How many prescription medications do you take regularly?" (continuous variable)

- "During the past month, have you forgotten to take your medication(s) for any reason?" (yes/no)

- "In the past year, have you not filled a new prescription or stopped taking a prescription medication because of the cost?" (yes/no)

- "In a typical month, from how many pharmacies do you get prescriptions, including mail order?" (continuous variable)

- "Have you been admitted into a hospital in the past 6 months?" (yes/no)

- "How many physicians have prescribed medications for you in the past year?" (continuous variable)

- "Please tell me the number of medical conditions for which you are receiving treatment" (continuous variable)

In addition to the MUSE tool, participants were also asked these questions:

- "Do you take any over-the-counter medications, vitamins, herbs, or supplements regularly?" (yes/no)

- "Do you take any medication without knowing what it is for?" (yes/no)

- "Have you had any side effects or unwanted reactions from your medication in the past 6 months?" (yes/no)

Health status was assessed using the single-item measure of general self-rated health where patients rate their health as "excellent," "very good," "good," "fair," or "poor" in response to the question "In general, compared to other people of your age, would you say your health is...." This measure showed good reproducibility and reliability, as well as strong concurrent and discriminant scale performance with an established health status measure. ${ }^{17}$
The 3-item adherence estimator was used to measure 3 proximal beliefs related to nonadherence: (1) "I worry that my prescription medication will do me more harm than good"; (2) "I am convinced of the importance of my prescription medication"; and (3) "I feel financially burdened by my out-of-pocket expenses for my prescription medication." ${ }^{19}$ Participants responded using an "agree" or "disagree" scale, and then a subscale of "somewhat," "mostly," or "completely." The adherence estimator was designed to segment patients on their propensity to adhere to a newly prescribed medication and showed excellent sensitivity. ${ }^{18}$

Finally, intention to obtain a CMR was assessed by asking participants "How likely are you to schedule an appointment with a pharmacist for a CMR in the next 30 days?" Responses to this question were assessed using a 5-point Likert scale where 5 was "very likely" and 1 was "very unlikely."

Data provided by Outcomes MTM included information on patients who obtained a CMR in the subsequent 6 months and pharmacies where patients obtained their medications. Information about which subjects received a CMR was linked to the survey data described above. Other demographic data such as age, sex, and number of prescription claims also were collected from enrollment data at the health plan and linked to the survey responses and claims data.

\section{Data Analysis}

Descriptive statistical analyses were performed for the independent variables. Counts and percentages were reported for categorical variables (sex, side effects from medications, forgetting to take medication in the last month, not filling a prescription due to cost, taking over-the-counter medications, taking medications without knowing what they are for, hospitalization in the last 6 months, and completed a CMR). Means and standard deviations (SDs) were reported for continuous variables (age, number of medications, number of pharmacies, number of prescribing doctors, and number of medical conditions) and ordinal variables (worry about more harm than good from medications, importance of medications, feeling financially burdened, health status, and likelihood of obtaining a CMR).

Two dependent variables were predicted: intention to schedule a CMR using a multivariate linear regression model and receipt of a CMR using a logistic regression and including intention as a predictor variable. In the regressions, 2 respondents were omitted because their data represented statistical outliers with regard to the number of medications (these individuals reported taking 30 and 57 medications, respectively). Therefore, the final sample used for all analyses was $n=660$. For the linear model, standardized coefficients were also calculated as a measure of effect sizes for the predictors. A casecontrol analysis was used to predict receipt of CMR since a CMR was considered a rare event. The cases were defined as all participants who obtained a CMR from their pharmacies, 


\begin{tabular}{|c|c|c|c|c|}
\hline & \multicolumn{2}{|c|}{$\begin{array}{l}\text { All Respondents } \\
\quad(n=660)\end{array}$} & \multicolumn{2}{|c|}{$\begin{array}{l}\text { Case-Control Sample } \\
(\mathrm{n}=141)\end{array}$} \\
\hline & \multicolumn{2}{|c|}{ Frequency (\%) } & \multicolumn{2}{|c|}{ Frequency (\%) } \\
\hline Male & 190 & $(28.8)$ & 39 & $(27.7)$ \\
\hline Female & 470 & $(71.2)$ & 102 & $(72.3)$ \\
\hline Experienced side effects in past 6 months (Y/N) & 107 & $(16.5)$ & 25 & $(18.2)$ \\
\hline Forgot to take medications for any reason in past month (Y/N) & 120 & $(18.2)$ & 28 & $(19.9)$ \\
\hline Did not fill or stopped medication due to cost in past year (Y/N) & 80 & $(12.1)$ & 19 & $(13.5)$ \\
\hline Took any OTC medications or supplements regularly (Y/N) & 553 & $(84.2)$ & 115 & $(81.6)$ \\
\hline Took any medication without knowing what it was for $(\mathrm{Y} / \mathrm{N})$ & 67 & $(10.2)$ & 18 & $(12.9)$ \\
\hline Admitted into a hospital in the past 6 months (Y/N) & 122 & $(18.5)$ & 25 & $(17.7)$ \\
\hline \multirow[t]{2}{*}{ Had a comprehensive medication review (CMR) (Y/N) } & 36 & $(5.6)$ & 36 & $(26.7)$ \\
\hline & \multicolumn{2}{|c|}{ Mean (SD) } & \multicolumn{2}{|c|}{ Mean (SD) } \\
\hline Age (as of January 2011) & 76.6 & $(7.61)$ & 76.1 & $(7.58)$ \\
\hline Number of medications taken regularly & 5.20 & $(3.18)$ & 5.25 & $(3.02)$ \\
\hline Number of pharmacies & 1.09 & $(0.31)$ & 1.11 & $(0.37)$ \\
\hline Number of prescribing doctors & 2.04 & $(1.25)$ & 2.13 & $(1.35)$ \\
\hline Number of medical conditions & 2.98 & $(1.60)$ & 3.07 & $(1.65)$ \\
\hline Worried medication will do more harm than good ${ }^{a}$ & 1.96 & $(1.35)$ & 1.93 & $(1.28)$ \\
\hline Felt financially burdened by medication expenses ${ }^{\mathrm{a}}$ & 3.30 & $(1.89)$ & 3.53 & $(1.80)$ \\
\hline Convinced of importance of prescription medications ${ }^{\mathrm{a}}$ & 5.61 & $(0.83)$ & 5.50 & $(0.88)$ \\
\hline Health statusb & 2.71 & $(1.05)$ & 2.53 & $(0.96)$ \\
\hline Likelihood of having a CMR in the next monthc & 2.85 & $(1.41)$ & 2.80 & $(1.37)$ \\
\hline \multicolumn{5}{|c|}{$\begin{array}{l}a_{\text {agree }}=1 \text {, disagree }=2 \text {, some what disagree }=3, \text { mostly disagree }=2 \text {, completely disagree }=1 . \\
b_{\text {excellent }}=1 \text { to poor }=5 . \\
{ }_{\text {very likely }=5 \text { to very unlikely }=1 .} \\
C M R=\text { comprehensive medication review; } N=\text { no; OTC = over the counter; } S D=\text { standard deviation; } Y=\text { yes. }\end{array}$} \\
\hline
\end{tabular}

either face-to-face or over the telephone; the controls were all individuals out of the 660 who went to the same pharmacies but did not have a CMR. Selecting controls from the same pharmacy ensured that every person in our study had an opportunity to have a CMR and also assisted with neighborhood matching where the individuals were assumed to be more demographically similar. All statistical analyses were performed with SPSS version 22 (IBM Corp., Armonk, NY) and $\mathrm{R}$ software (R Foundation for Statistical Computing, Vienna, Austria). Standardized coefficients were calculated using the R module QuantPsyc version 1.5. ${ }^{19}$

\section{Results}

$\overline{T h e}$ mean age of participants $(\mathrm{n}=660)$ was 76.6 years $(\mathrm{SD}=7.61)$; $71 \%$ were female; and participants took an average of 5.2 medications ( $\mathrm{SD}=3.18$; Table 1). Beneficiaries reported a mean likelihood of obtaining a CMR of 2.85 (1.41) out of 5, and 35.7\% $(n=116+118$, data not shown) indicated they would be either likely or very likely to schedule a CMR in the following month. Of the 660 participants who completed the telephone survey, 36 (5.6\%) had CMRs performed by their pharmacists (cases). A total of 105 beneficiaries who obtained their medications from the same pharmacies but did not have a CMR were used as controls in predicting behavior. The 660 respondents obtained their medications from a total of 216 pharmacies, a mean of $3.1(\mathrm{SD}=4.2)$ participants per pharmacy. The 141 respondents in the case-control sample obtained their medications from 24 different pharmacies, which corresponds to a mean of 5.9 ( $\mathrm{SD}=8.8$, data not shown) participants per pharmacy.

The unadjusted analyses in considering intention to obtain a CMR showed that most variables were associated with an individual's stated intention to obtain a CMR. The 3 strongest predictors of intention were number of pharmacies (standardized regression coefficient $[\beta]=0.76 ; 95 \%$ confidence interval $[\mathrm{CI}]=0.42-1.10$ ), forgetting to take medications $(\beta=0.41 ; 95 \% C I=0.14-0.69)$, and not knowing what medications were for $(\beta=0.38$; 95\% CI $=0.02-0.74$; Table 2). The multivariate linear regression model predicting intention to obtain a CMR accounted for more than $10 \%$ of variance (adjusted $\mathrm{R}^{2}=0.11$; multiple $\mathrm{R}^{2}=0.13$; Table 3 ). The strongest predictor of intention was number of pharmacies $(\beta=0.47$; $95 \% \mathrm{CI}=0.09-0.85)$ followed by worry that medication caused more harm than good $(\beta=0.11 ; 95 \% \mathrm{CI}=0.02-0.20)$, number of medical conditions $(\beta=0.08 ; 95 \% \mathrm{CI}=0.00-0.17)$, and number of medications ( $\beta=0.07 ; 95 \% \mathrm{CI}=0.02-0.11$ ).

In predicting behavior, the unadjusted coefficients for obtaining a CMR showed that intention to obtain a CMR (odds ratio $[\mathrm{OR}]=1.34 ; 95 \% \mathrm{CI}=1.00-1.80$ ) was independently asso- 


\begin{tabular}{|c|c|c|c|c|c|c|}
\hline \multirow{3}{*}{$\begin{array}{l}\text { Variable } \\
\text { Age (as of January 2011) }\end{array}$} & \multicolumn{3}{|c|}{$\begin{array}{l}\text { Intention to Obtain a CMR } \\
\qquad(\mathrm{n}=660)\end{array}$} & \multicolumn{3}{|c|}{$\begin{array}{l}\text { Receipt of a CMR } \\
(n=141)\end{array}$} \\
\hline & \multicolumn{2}{|c|}{$\begin{array}{c}\text { Unadjusted } \\
\beta \text { and } 95 \% \text { CI }\end{array}$} & \multirow{2}{*}{$\frac{P \text { Value }}{0.59}$} & \multicolumn{2}{|c|}{$\begin{array}{c}\text { Unadjusted } \\
\text { OR and } 95 \% \text { CI }\end{array}$} & \multirow{2}{*}{$\frac{P \text { Value }}{0.87}$} \\
\hline & 0.00 & $-0.02-0.01$ & & 1.00 & $0.94-1.05$ & \\
\hline Sex (female, reference) & -0.05 & $-0.29-0.19$ & 0.69 & 0.69 & $0.28-1.69$ & 0.42 \\
\hline Number of medications (no, reference) & 0.12 & $0.09-0.15$ & $<0.01$ & 1.04 & $0.92-1.18$ & 0.49 \\
\hline Side effects in past 6 months (no, reference) & 0.34 & $0.04-0.63$ & 0.02 & 1.08 & $0.39-3.04$ & 0.88 \\
\hline Worry more harm than good ${ }^{a}$ & 0.17 & $0.09-0.25$ & $<0.01$ & 1.20 & $0.89-1.62$ & 0.24 \\
\hline Financially burdened $^{a}$ & 0.09 & $0.03-0.15$ & $<0.01$ & 0.92 & $0.74-1.14$ & 0.43 \\
\hline Health status ${ }^{b}$ & 0.22 & $0.12-0.32$ & $<0.01$ & 1.35 & $0.90-2.02$ & 0.15 \\
\hline Forgot to take medications (no, reference) & 0.41 & 0.14-0.69 & $<0.01$ & 1.29 & $0.50-3.28$ & 0.60 \\
\hline Not filled or taken due to cost (no, reference) & 0.22 & $-0.11-0.55$ & 0.19 & 0.83 & $0.25-2.72$ & 0.75 \\
\hline OTC or supplements (no, reference) & 0.24 & $-0.06-0.53$ & 0.12 & 1.04 & $0.37-2.88$ & 0.94 \\
\hline Not knowing what medications are for (no, reference) & 0.38 & $0.02-0.74$ & 0.04 & 2.54 & $0.92-7.07$ & 0.07 \\
\hline Importance of medications ${ }^{\mathrm{a}}$ & 0.02 & $-0.11-0.15$ & 0.77 & 1.01 & $0.59-1.71$ & 0.98 \\
\hline Hospitalized in past 6 months (no, reference) & 0.29 & $0.01-0.57$ & 0.04 & 1.38 & $0.54-3.54$ & 0.51 \\
\hline Number of pharmacies & 0.76 & $0.42-1.10$ & $<0.01$ & 0.69 & $0.23-2.06$ & 0.50 \\
\hline Number of prescribing doctors & 0.21 & $0.12-0.29$ & $<0.01$ & 1.00 & $0.75-1.33$ & 0.98 \\
\hline Number of medical conditions & 0.23 & $0.17-0.30$ & $<0.01$ & 1.02 & $0.81-1.29$ & 0.85 \\
\hline Likelihood of having a CMR in the next month & - & - & - & 1.34 & $1.00-1.80$ & 0.05 \\
\hline \multicolumn{7}{|c|}{ 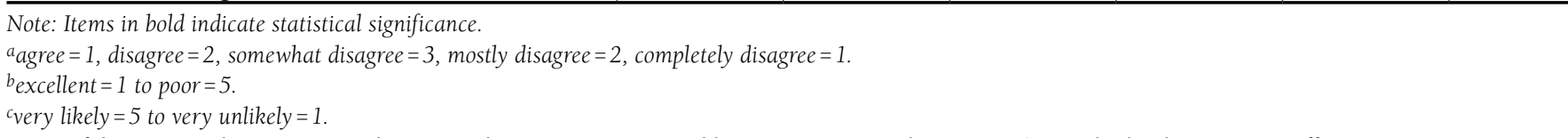 } \\
\hline
\end{tabular}

ciated with this health behavior (Table 2). The logistic regression model predicting receipt of a CMR accounted for more than 20\% of variance (area under the curve $=0.75$; Nagelkerke $\mathrm{R}^{2}=0.21$; Table 4). The only statistically significant predictor in the multivariate model was poor health status, with $\mathrm{OR}=2.25$ (95\% CI $=1.19-4.26)$.

\section{Discussion}

$\overline{\text { Of the } 660 \text { participants included in this study, 35\% indicated }}$ that they would be either likely or very likely to schedule an appointment with a pharmacist for a CMR within the following 30 days. However, only about $6 \%$ of participants actually had a CMR performed by their pharmacist. This figure is similar to others reported by previous authors ${ }^{6,13}$ but is almost half of that reported in another study that approached $13 \% .{ }^{11}$ The latter study aimed to describe the types of medication issues and recommendations identified in the Iowa Priority Brown Bag Medication Reviews before the inception of the Medicare Part D program. This program was launched by the state and promoted as a means of helping patients save money on their medication, which might have accounted for the higher percentage of individuals obtaining a CMR. ${ }^{11}$

In terms of predicting intention, the multivariate model demonstrated that the number of medical conditions, number of pharmacies, number of medications, and worry about having more harm than good from medications predicted an individual's intention to schedule a CMR. Previous research showed that concerns about managing health conditions and the number of prescribed medications, as well as patients' perceived need to receive more information about medications and to be assured of the medication therapy appropriateness, were strong motivations to obtain a CMR. ${ }^{6}$

The only variable that was predictive of behavior (receipt of a CMR) was poor health status. This is consistent with a previous study that revealed that older adults who reported poorer health status and who had more complex medication regimens were more likely to demand a CMR service. ${ }^{20}$ Therefore, screening for patients who self-report poor health status within a community pharmacy setting could be a means of promoting the use of CMR services in the future. Other supporting evidence suggests that patients who perceived poorer health and who had more self-reported conditions and more prescribed medications were the ones who presented with the most medication issues during a $\mathrm{CMR}^{11}$ and were the most likely to benefit from the service. However, a positive answer to the question: "How likely are you to schedule an appointment with a pharmacist for a CMR in the next 30 days?" did not predict actual behavior. Other barriers not accounted for in our model, such as knowing how to schedule or where to obtain a CMR, may contribute to this finding, and it warrants further 
TABLE 3 Multivariate Linear Regression Predicting Intention to Obtain a CMR (N=660)

\begin{tabular}{|c|c|c|c|c|}
\hline Variable & $\beta$ & $95 \%$ CI & Standardized $\beta$ & $P$ Value \\
\hline \multicolumn{5}{|l|}{ Adjusted $\mathrm{R}^{2}=0.11$, Multiple $\mathrm{R}^{2}=0.13$} \\
\hline Age (as of January 2011) & 0.00 & $-0.02-0.01$ & -0.01 & 0.87 \\
\hline Sex (female, reference) & 0.01 & $-0.24-0.26$ & 0.00 & 0.93 \\
\hline Number of medications (no, reference) & 0.07 & $0.02-0.11$ & 0.15 & $<0.01$ \\
\hline Side effects in past 6 months (no, reference) & 0.18 & $-0.12-0.49$ & 0.05 & 0.24 \\
\hline Worry more harm than gooda & 0.11 & $0.02-0.20$ & 0.10 & 0.02 \\
\hline Financially burdened ${ }^{\mathrm{a}}$ & 0.04 & $-0.03-0.10$ & 0.05 & 0.26 \\
\hline Health status ${ }^{b}$ & 0.05 & $-0.07-0.16$ & 0.03 & 0.45 \\
\hline Forgot to take medications (no, reference) & 0.11 & $-0.18-0.40$ & 0.03 & 0.46 \\
\hline Not filled or taken due to cost (no, reference) & 0.03 & $-0.31-0.37$ & 0.01 & 0.85 \\
\hline OTC or supplements (no, reference) & 0.07 & $-0.24-0.38$ & 0.02 & 0.65 \\
\hline Not knowing what medications are for (no, reference) & 0.04 & $-0.33-0.41$ & 0.01 & 0.84 \\
\hline Importance of medications $s^{\mathrm{a}}$ & 0.06 & $-0.08-0.20$ & 0.04 & 0.37 \\
\hline Hospitalized in past 6 months (no, reference) & -0.01 & $-0.31-0.28$ & 0.00 & 0.93 \\
\hline Number of pharmacies & 0.47 & $0.09-0.85$ & 0.10 & 0.02 \\
\hline Number of prescribing doctors & 0.07 & $-0.03-0.17$ & 0.06 & 0.15 \\
\hline Number of medical conditions & 0.08 & $0.00-0.17$ & 0.10 & 0.05 \\
\hline \multicolumn{5}{|c|}{$\begin{array}{l}\text { Note: } \text { Items in bold indicate statistical significance. } \\
\text { a agree }=1 \text {, disagree }=2 \text {, somewhat disagree }=3 \text {, mostly disagree }=2 \text {, completely disagree }=1 . \\
\text { bexcellent }=1 \text { to poor }=5 \text {. } \\
C I=\text { confidence interval; } C M R=\text { comprehensive medication review; OTC = over the counter; } \beta=\text { standardized regression coefficient. }\end{array}$} \\
\hline
\end{tabular}

research. An approach where implementation intentions are used as part of an intervention would be helpful to convert intentions into behavior. ${ }^{21}$ In such an intervention, potential participants would be prompted to state or document how, when, and where they could obtain a CMR. This type of cognitive intervention, rather than simply telling individuals where to obtain a CMR, helps individuals plan future behavior, and this simple intervention results in higher consistency between intention and behavior. ${ }^{22}$

Examining physicians' support of CMRs in future studies would also shed light on potential interventions at the provider level that could contribute to the expansion of the service. In Australia, where a similar service is provided by pharmacists (e.g., Home Medicines Review), it has been found that general practitioners' social influence affects acceptance of medication review services by patients. ${ }^{23}$ Likewise, if physicians promoted pharmacist-delivered CMR services in the United States, it would be expected that patients would be more likely to believe that having a CMR conducted by a pharmacist was beneficial. Although the number of physicians was not a significant predictor in any of the models tested in our study, another investigation showed that patients who were prescribed medications by several physicians had a higher probability of obtaining a medication review. ${ }^{20}$

Other variables that were expected to predict but did not show any influence in the behavior of obtaining a CMR included age, sex, and experience of side effects. Older age and female sex were found to increase the likelihood of obtaining a medication review in another study, ${ }^{20}$ and experiencing side effects was a determinant in deciding to participate in a CMR service. ${ }^{6}$ For $16 \%$ of patients in the latter study, a CMR was seen as an opportunity to meet with the pharmacist and mitigate side effect issues. ${ }^{6}$ In our study, $16.5 \%$ of individuals said they were experiencing side effects but this variable did not predict obtaining a CMR

Another of the variables tested in the model that was not associated with obtaining a CMR was feeling financially burdened by medication expenses. It seems that individuals with concerns about their medication costs would be more likely to have a CMR to talk with pharmacists to determine if less expensive medications could be identified.

In our study, a concerning percentage of participants selfreported forgetting medications, taking medications for which the reasons were not known, or purposefully not taking medications due to cost. These simple findings suggest that older adults may benefit from having additional education, documentation, or support regarding their medications, and these services are an integral part of an MTM service, even though these factors were not associated with either intention to have or receipt of a CMR.

At the present time, most health plans identify Medicare Part D beneficiaries who are eligible to receive MTM services by the analysis of prescription claims data. A first step in collecting patient-reported information to increase participation in CMRs among beneficiaries was the creation and the design of an intervention using the MUSE tool. ${ }^{16}$ This current analysis 
TABLE 4 Logistic Regression Predicting Receipt of a CMR (N=141)

\begin{tabular}{|c|c|c|c|}
\hline Variable & OR & $95 \%$ CI & $P$ Value \\
\hline \multicolumn{4}{|l|}{ AUC $=0.75$, Nagelkerke $\mathrm{R}^{2}=0.21$} \\
\hline Age (as of January 2011) & 0.97 & $0.91-1.04$ & 0.44 \\
\hline Sex (female, reference) & 0.66 & $0.21-2.05$ & 0.47 \\
\hline Number of medications (no, reference) & 1.03 & $0.84-1.27$ & 0.74 \\
\hline Side effects in past 6 months (no, reference) & 1.52 & $0.41-5.64$ & 0.53 \\
\hline Worry more harm than gooda & 1.07 & $0.72-1.60$ & 0.73 \\
\hline Financially burdened ${ }^{a}$ & 0.79 & $0.59-1.05$ & 0.10 \\
\hline Health status ${ }^{b}$ & 2.25 & $1.19-4.26$ & 0.01 \\
\hline Forgot to take medications (no, reference) & 1.18 & $0.34-4.13$ & 0.79 \\
\hline Not filled or taken due to cost (no, reference) & 0.99 & $0.24-4.18$ & 0.99 \\
\hline OTC or supplements (no, reference) & 0.80 & $0.20-3.16$ & 0.74 \\
\hline Not knowing what medications are for (no, reference) & 2.56 & $0.57-11.53$ & 0.22 \\
\hline Importance of medications ${ }^{\mathrm{a}}$ & 1.16 & $0.57-2.37$ & 0.68 \\
\hline Hospitalized in past 6 months (no, reference) & 2.03 & $0.63-6.55$ & 0.23 \\
\hline Number of pharmacies & 0.88 & $0.22-3.47$ & 0.85 \\
\hline Number of prescribing doctors & 1.00 & $0.65-1.54$ & 0.99 \\
\hline Number of medical conditions & 0.82 & $0.54-1.25$ & 0.37 \\
\hline Likelihood of having a CMR in the next monthc & 1.24 & $0.85-1.81$ & 0.26 \\
\hline \multicolumn{4}{|c|}{$\begin{array}{l}\text { Note: Item in bold indicates statistical significance. } \\
\text { agree }=1 \text {, disagree }=2 \text {, somewhat disagree }=3, \text { mostly disagree }=2 \text {, completely disagree }=1 . \\
\text { bexcellent }=1 \text { to poor }=5 \text {. } \\
\text { cery likely }=5 \text { to very unlikely }=1 \text {. } \\
\text { AUC = area under the curve; } C I=\text { confidence interval; } C M R=\text { comprehensive medication review; OR=odds ratio; OTC=over the counter. }\end{array}$} \\
\hline
\end{tabular}

represents another step forward in that it assessed the influence of other variables beyond the ones tested with the MUSE tool. If health plans are interested in increasing the number of beneficiaries who have a CMR, as this activity will influence Medicare plan quality ratings, they should first identify individuals who perceive their health to be poor and then use a cognitive intervention to translate intention into behavior. Externally motivating individuals by paying them to receive a CMR would be another strategy, which would be in line with behavioral economics. As the self-reported variables in this dataset are not available from claims data, an alternative model could have pharmacists or pharmacy staff collect this information at the point of care (community pharmacy), and the information could then be forwarded to payers and linked to patient claims data. These data could then be used to generate alerts for pharmacists through the pharmacy software to help them target and refer patients for a CMR service. Such an approach would move practice beyond using only claims data. The importance of having patients self-report health information versus using claims data exclusively has been highlighted in a recent study that identified discrepancies between patientreported information regarding chronic comorbidities and medications and diagnostic billing data (ICD-9-CM codes for chronic comorbidities) and pharmacy claims data (medications). ${ }^{24}$

\section{Limitations}

Our study presents some limitations. Data were obtained from a single health plan, thereby limiting generalizability. As well, a small number of beneficiaries actually received a CMR. Therefore, some of the variables that were shown to have no effect in our analysis could become statistically significant predictors of intention and CMR receipt in a larger sample. The 6-month period selected for data collection was longer than the time frame stated in the intention question, and this could account for its inability to predict behavior. However, the longer time frame was used to allow enough time for patients to be able to schedule and obtain a CMR. Finally, 2 outliers were removed from the regression analyses.

\section{Conclusions}

Worrying about medications doing more harm than good, number of medical conditions, number of medicines, and number of pharmacies where participants acquired their medications predicted intention to obtain a CMR. A positive relationship between patients who reported poorer health status and having a CMR was found. However, a positive answer to the question assessing intention to obtain a CMR in the following 30 days was not associated with the actual behavior to obtain a CMR. Patient self-report information can be used by health plans and other stakeholders to target Medicare Part D beneficiaries for CMRs by working in collaboration with community pharmacies. 


\section{Authors}

KAREN B. FARRIS, PhD, is Charles R. Walgreen III Professor of Pharmacy Administration; TERESA M. SALGADO, PhD, is Postdoctoral Research Fellow; and VINCENT D. MARSHALL, MS, is Statistician, Department of Clinical Pharmacy, University of Michigan College of Pharmacy, Ann Arbor. JANE F. PENDERGAST, PhD, is Professor of Biostatistics, Department of Biostatistics, and ELIZABETH A. CHRISCHILLES, PhD, is Professor and Marvin A. and Rose Lee Pomerantz Chair in Public Health, and Director, Health Effectiveness Research Center, University of Iowa College of Public Health, Iowa City. NADIA ANEESE, PharmD, is Ambulatory Care Pharmacy Resident, Beaumont Health System, Troy, Michigan; JESSICA FRANK, PharmD, is Vice President of Quality, Outcomes MTM, West Des Moines, Iowa; and WILLIAM R. DOUCETTE, $\mathrm{PhD}$, is Professor and Head, Division of Health Services Research, Department of Pharmacy Practice and Science, University of Iowa College of Pharmacy, Iowa City.

AUTHOR CORRESPONDENCE: Karen B. Farris, PhD, Professor of Pharmacy Administration, Department of Clinical Pharmacy, University of Michigan College of Pharmacy, 428 Church St., Ann Arbor, MI 48109. Tel.: 734.763.5150; E-mail:kfarris@umich.edu.

\section{DISCLOSURES}

This study was funded by a grant from the Agency for Healthcare Research and Quality (1R18HS018353). Frank is an employee of Outcomes MTM. Pendergast has received grants from the NIH, NIA, and PICORI. Farris has received grants from NIH and speaker fees from Chulalongkorn University, Bangkok, Thailand, and the American College of Clinical Pharmacy. All other authors declare that they have no conflicts of interest.

Study concept was developed by Farris, Pendergast, Chrischilles, and Doucette. Pendergast, Frank, Farris, and Aneese collected the data, with assistance from Chrischilles and Doucette. Data interpretation was performed by Farris, Marshall, Salgado, and Aneese, with assistance from the other authors. The manuscript was written by Farris, Salgado, and Aneese, with assistance from the other authors, and revised by Salgado and Marshall, assisted by the other authors.

\section{REFERENCES}

1. Government Printing Office. Medicare Prescription Drug, Improvement, and Modernization Act of 2003. Available at: http://www.gpo.gov/fdsys/pkg/ PLAW-108publ173/pdf/PLAW-108publ173.pdf. Accessed January 3, 2016. 2. Centers for Medicare \& Medicaid Services. Prescription Drug Benefit Manual. Chapter 7-Medication Therapy Management and Quality Improvement Program. 2010. Available at: http://www.cms.gov/Medicare/ Prescription-Drug-Coverage/PrescriptionDrugCovContra/Downloads/ Chapter7.pdf. Accessed January 3, 2016.

3. American Pharmacists Association and the National Association of Chain Drug Stores Foundation. Medication therapy management in pharmacy practice: core elements of an MTM service model (version 2.0). J Am Pharm Assoc. 2008;48(3):341-53.

4. Centers for Medicare \& Medicaid Services. Memo: Contract Year 2015 Medication Therapy Management (MTM) Program Submission (v. 05.07.14). Available at: http://www.cms.gov/Medicare/Prescription-Drug-Coverage/ PrescriptionDrugCovContra/Downloads/ MemoContractYear2015 MedicationTherapyManagementProgram Submission050714.pdf. Accessed January 3, 2016.

5. Stuart B, Loh E, Miller L, Roberto P. Should eligibility for medication therapy management be based on drug adherence? J Manag Care Pharm. 2014; 20(1):66-75. Available at: http://www.jmcp.org/doi/abs/10.18553/ jmcp.2014.20.1.66.

6. Shimp LA, Kucukarslan SN, Elder J, et al. Employer-based patient-centered medication therapy management program: evidence and recommendations for future programs. J Am Pharm Assoc. 2012;52(6):768-76.
7. Desborough JA, Sach T, Bhattacharya D, Holland RC, Wright DJ. A costconsequences analysis of an adherence focused pharmacist-led medication review service. Int J Pharm Pract. 2012;20(1):41-49.

8. Wittayanukorn S, Westrick SC, Hansen RA, et al. Evaluation of medication therapy management services for patients with cardiovascular disease in a self-insured employer health plan. J Manag Care Pharm. 2013;19(5):385-95. Available at: http://www.jmcp.org/doi/abs/10.18553/jmcp.2013.19.5.385.

9. Moore JM, Shartle D, Faudskar L, Matlin OS, Brennan TA. Impact of a patient-centered pharmacy program and intervention in a high-risk group. J Manag Care Pharm. 2013;19(3):228-36. Available at: http://www.jmcp.org/ doi/abs/10.18553/jmcp.2013.19.3.228.

10. Ramalho de Oliveira D, Brummel AR, Miller DB. Medication therapy management: 10 years of experience in a large integrated health care system. J Manag Care Pharm. 2010;16(3):185-95. Available at: http://www.jmcp.org/ doi/abs/10.18553/jmcp.2010.16.3.185.

11. Farris KB, Ganther-Urmie JM, Fang G, et al. Population-based medication reviews: a descriptive analysis of the medication issues identified in a Medicare not-for-profit prescription discount program. Ann Pharmacother. 2004;38(11):1823-39.

12. Hirsch JD, Gonzales M, Rosenquist A, et al. Antiretroviral therapy adherence, medication use, and health care costs during 3 years of a community pharmacy medication therapy management program for Medi-Cal beneficiaries with HIV/AIDS. J Manag Care Pharm. 2011;17(3):213-23. Available at: http://www.jmcp.org/doi/abs/10.18553/jmcp.2011.17.3.213.

13. Rucker NL. Medicare Part D's medication therapy management: shifting from neutral to drive. AARP Public Policy Institute. June 2012. Available at: http://www.aarp.org/content/dam/aarp/research/public_policy_institute/ health/medicare-part-d-shifting-from-neutral-to-drive-insight-AARP-ppihealth.pdf. Accessed January 3, 2016.

14. Doucette WR, Zhang Y, Chrischilles EA, et al. Factors affecting Medicare Part D beneficiaries' decision to receive comprehensive medication reviews. J Am Pharm Assoc. 2013;53(5):482-87.

15. Doucette WR, Chang EH, Pendergast JF, et al. Development and initial assessment of the medication user self-evaluation (MUSE) tool. Clin Ther. 2013;35(3):344-50.

16. Doucette WR, Pendergast JF, Zhang Y, et al. Stimulating comprehensive medication reviews among Medicare Part D beneficiaries. Am J Manag Care. 2015;21(6):e372-78

17. DeSalvo KB, Fisher WP, Tran K, et al. Assessing measurement properties of two single-item general health measures. Qual Life Res. 2006;15(2):191-201. 18. McHorney CA. The Adherence Estimator: a brief, proximal screener for patient propensity to adhere to prescription medications for chronic disease. Curr Med Res Opin. 2009;25(1):215-38.

19. Fletcher TD. QuantPsyc: Quantitative Psychology Tools. Version 1.5 2012. Available at: https://cran.r-project.org/web/packages/QuantPsyc/ QuantPsyc.pdf. Accessed January 28, 2016.

20. Brooks JM, Unni EJ, Klepser DG, et al. Factors affecting demand among older adults for medication therapy management services. Res Social Adm Pharm. 2008;4(4):309-19.

21. Brandstatter V, Lengfelder A, Gollwitzer PM. Implementation intentions and efficient action initiation. J Pers Soc Psychol. 2001;81(5):946-60.

22. Armitage CJ. Field experiment of a very brief worksite intervention to improve nutrition among health care workers. J Behav Med. 2015;38(4):599-608. 23. Carter SR, Moles RJ, White L, Chen TF. Consumers' willingness to use a medication management service: the effect of medication-related worry and the social influence of the general practitioner. Res Social Adm Pharm. 2013;9(4):431-45.

24. Roane TE, Patel V, Hardin H, Knoblich M. Discrepancies identified with the use of prescription claims and diagnostic billing data following a comprehensive medication review. J Manag Care Pharm. 2014;20(2):165-73. Available at: http://www.jmcp.org/doi/abs/10.18553/jmcp.2014.20.2.165. 